\title{
CAREER ADVANCEMENT STAGNATION AMONG PUBLIC SCHOOL TEACHERS IN TACLOBAN CITY: A PHENOMENOLOGICAL STUDY
}

\author{
Reynaldo P. Pagayanan, EdD
}

Department of Education, Tacloban City, 6500 Philippines

\begin{abstract}
Career advancement stagnation refers to the phenomenon on the immobility of the teaching career from the entry level position to the present for 10 years or more without changes on duties and responsibilities. This study aims to describe the lived experiences of public elementary and secondary school teachers in Tacloban City on career advancement stagnation: its reasons, challenges and coping mechanisms. It is a qualitative research using transcendental phenomenological approach (Cohen, et.al.,2011) involving eight (8) participants. Analysis of data was done using Colaizzi's method (1978) of thematic analysis. Results of the study revealed the following themes on the lived experiences of the public school teachers: professional learning and development, organizational support, organizational communication and work environment. Emerging themes on the reasons of experiencing career advancement stagnation are lack of financial resources, low educational qualifications, work pressure, promotion anxiety, lack of support and career decisions. The participants also highlighted positive and negative coping mechanisms while experiencing different challenges on the said phenomenon. It is concluded that career stagnation of public school teachers are caused by individual and organizational dimensions and its interaction towards career goals. It is then recommended that an intervention and enhancement program be proposed to further improve the career development scheme of public school teachers.
\end{abstract}

Keywords: career advancement stagnation, career stagnation, human resource management, public school teachers

\section{INTRODUCTION}

Career is a process where the person, not the organization, is the manager of the process (Hall, 2002). His definition states that a career is individually perceived sequence of attitudes and behaviours associated with work-related experiences and activities over the span of the person's life. In an occupational standpoint, career is the sum total of the various jobs an individual holds for a lifetime. It directs educational, social, economic, political and spiritual endeavors and reflect the unique personality of a person and his basic life values (Phiper, 2003). Thus, the success of one's career in employment rely on the individual and the opportunities available for him in an organization.

Career development is the primary mechanism that schools can use to help teachers continuously learn and improve their skills over time in order to ensure that the roles will be carried out (Glossary of Education Reforms, 2013). It is a wide variety of specialized training, formal education, or advanced professional learning intended to help administrators, teachers, and other educators improve their professional knowledge, competence, skill, and effectiveness. It is important because it ensures to continue to be competent in the profession as it is an ongoing 
process and continues throughout a professional's career and excel in it. Having a career development plan will help individuals to keep track on their progress and identify the most relevant opportunities to improve themselves and achieve professional objectives (Kloosterman, 2018). In the Philippines, career advancement of teachers in the Department of Education comes in career stages from Teacher I to Teacher III to Master Teacher I to Master Teacher IV for Teaching Career Line or Principal I to Principal IV for Administrative Career Line (DBM Manual, 2004).

Citing DepEd Order 11, s. 2018, out of 773, 391 teaching population, 400, 062 are entry level positions or 52 percent are entry-level teachers while there are only 53, 259 items, or $6.8 \%$ of the total that are occupied by Master Teachers (MT I to MT III). Moreover, these problems in the system of promotion, according to Congressman France Castro, have kept teachers at the entry level or Teacher I position for almost 15 or more years, with many of them retiring as Teacher I (Cruz, 2018). Thus, experiencing career advancement stagnation.

Stagnation is a state in which the teacher feels confident where she is, and thus does not feel the need to advance and realize her full potential. This state of stagnation might derive from lack of empowerment by the organization she works for, or from a lack of possibilities for professional development. As a result, the teacher feels weak and of little value, which then affects her desire to advance within the system. People like this will find themselves in the same job for a long time, and even if they do not like their position, they will find it hard to leave (Zamir, 2018). Abele, Volmer and Spurk (2012) averred that career stagnation may cover two reasons - lack of career opportunities and organizational conditions. The former refers to individual and interpersonal factors such as self-efficacy issues, goal issues, and dual career issues while the latter refers to socialization, support, mentoring, bullying, mobbing, stereotypes and discrimination. Since teaching career involves students, underlying effects of career stagnation may have negative impact to the employee and the organization including, but not limited to, job performance, learners' achievement and quality of education. The dearth of the empirical data on career stagnation pushes the researcher to explore the experiences of these teachers.

Considering the above mentioned premises, public school teachers in Tacloban City Division are not exempted on this kind of phenomenon. It reveals that there are 198 teachers who have experienced career advancement stagnation for more than ten years. Among the ten districts, DLC IV got the highest number of teachers who experienced career advancement stagnation considering its population. While DLC I got the lowest number of teachers considering that most of these schools are newly established. Hence, there is a need to explore the lived experiences on career advancement stagnation of public school teachers with entry level position for 10 or more years in order to understand and explore its occurrence, challenges and difficulties they encountered vis-à-vis recruitment and selection, learning and development, rewards and strategies, performance management and motivation and workplace and regulations.

The findings of this study will aid the Department of Education and policy-makers to evaluate the current programs implemented and consider programs that will help improve the quality of life of teachers. This will also gain interest to common individuals and institutions to have a deeper understanding of the lives of teachers in the society. Generally, the study will describe the lived experiences of public school teachers in Tacloban City on career advancement 
stagnation in order to provide insights from specific patterns emerging as themes from the investigations. Specifically, the study sought to answer the following questions:

1. What are the lived experiences of the participants on career advancement stagnation?

2. Why did the participants experience career advancement stagnation?

3. How do these participants cope with career advancement stagnation?

\section{REVIEW OF LITERATURE}

Mobility and stagnation in a teacher's career are immanent to the career progress. Mobility is a process whereby a teacher has the opportunity to develop both personally and professionally. Stagnation is the opposite of mobility; it is a state in which the teacher feels confident where she is, and thus does not feel the need to advance and realize her full potential. This state of stagnation might derive from lack of empowerment by the organization she works for, or from a lack of possibilities for professional development. As a result, the teacher feels weak and of little value, which then affects her desire to advance within the system. People like this will find themselves in the same job for a long time, and even if they do not like their position, they will find it hard to leave (Zamir, 2018).

In a study conducted by Zamir (2018) titled "A Teaching Career: Mobility and Stagnation", she found out that the nature of the relationships with the school administrators and with other members of the teaching staff is the main cause of career stagnation. The participants claimed that the aspect on lack of cooperation with the principal, lack of goodwill, lack of appreciation and lack of trust between the principal and the members are the causes in particular. Lack of challenges and work overload were also highlighted. Most of the subjects reported personal conflicts between teachers and administrators as a career - impeding factor.

Farrel (2014), on the other hand, reported a qualitative study of the reflections of three midcareer female ESL teachers in Canada through the lens of their participation in a two-year teacher discussion group. The results indicate that some ESL teachers in mid-career may encounter some form of plateauing, but if they engage in collaborative group discussions with other teachers either within or outside their institutions, they can learn to better understand, and ultimately learn how to resist it and maintain their commitment and enthusiasm for their work as ESL teachers. Further, the study of Abele, Volmer and Spurk (2012) suggest self-efficacy and self-management trainings, career counseling, mentoring, anti-mobbing/anti-bullying interventions, recruitment strategies for dual-career couples, and anti-discrimination strategies in order to increase the quality of one's career thus eliminating career stagnation.

Relative to the effects of career stagnation, Nachbagauer and Riedl (2002) focuses on the independence of three dimensions of career plateaus and the impact they have on outcome measures in three areas: performance, work satisfaction and commitment. The study found out that contrary to the general assumption that an extended period working at the same position has detrimental effects, outcome variables were not connected to position immobility. Advances in work content can even moderate negative effects emanating from low expectations of hierarchical promotion. These have implications for individual and organizational career management processes.

Demel et.al. (2014) defined career as a process where the person, not the organization, is the manager of the process. His definition states that a career is individually perceived sequence of attitudes and behaviours associated with work-related experiences and activities over the span of 
the person's life. Career advancement, on the other hand, is basically having the opportunity to be promoted to a higher position or be given more responsibility in a current role (Wirtanen, 2018). In order to be promoted, career advancement encompasses an individual experience, training, education among others. Advancement, according to Mayhew (2019), has a broad definition such as a career move within or outside the same organization based on proficiency, work experience or training.

Considering that this study would like to describe the lived experiences of public school teachers on career advancement stagnation in Schools Division of Tacloban City, all these reviewed studies are considered relevant to the present study as they dealt on the career advancement stagnation of teachers - its causes and the underlying effects to the individual and organization. Factors such as recruitment and selection, learning and development, rewards systems and management, performance management and motivation and workplace relations and regulations were taken into account in order to better understand and describe the experiences of the teachers in the light of creating enhancement programs for human resource management in the Department of Education. Further, it can also be the basis of formulating empowerment programs that will allow the teachers to carefully plan their careers. The objectives of the current study are all similar to the studies reviewed.

\section{METHODOLOGY}

Research Design. This study is a qualitative research using phenomenological approach as it advocates the study of direct experience taken at a face value and one which sees behavior as determined by the phenomena of experience rather than by external, objective and physically described reality (Cohen, et.al.,2011). Specifically, the study utilized transcendental phenomenological research design based on the systematic approach of Moustakas (1994) in analyzing data about lived experiences. Laverty (2003) defined it as pure, descriptive or Husserlian Phenomenology whose concern is to study lived experiences and allows the development of a perspective inclusive of external, physical, isolatable stimuli. It erases the Cartesian dualism between subjectivity and objectivity by allowing researchers to develop the objective "essence" through aggregating subjective experiences of a number of individuals Since the study is aimed to describe the lived experiences of public elementary and secondary school teachers in Tacloban City who had served DepEd for 10 years or more with entry level position, this design is deemed to be appropriate.

Research Locale. The study is conducted in the Schools Division of Tacloban City with both secondary and elementary schools whose characteristics qualified as participants of the study based on the selection criteria.

Sampling Procedure. The participants of the study were public school teachers of Schools Division of Tacloban City which were identified through purposive sampling. This involves identifying and selecting individuals or groups of individuals that are especially knowledgeable about or experienced with a phenomenon of interest (Cresswell \& Plano Clark, 2011). This sampling method was utilized since the researcher only included the participants whose characteristics qualify the objective of the study through the participant selection criterion as follows: (a)The participant has an entry level position in the Department of Education for10 years or more and, (b) the participant is willing to participate and has the ability to communicate experiences and opinions. Since the participants' profile were not available in the Records and 
Services Section of the department, participants were identified by the researcher by getting the information from the school head using a profiling template on teaching experiences per teaching positions.

Data Collection. The data gathering procedure started with request to grant permission from the Schools Division Superintendent to conduct the study in the premise of the Department of Education. Then, the researcher contacted the participants. After the confirmation to agree on time, the researcher personally met each participant and gave an orientation about the purpose of the study. When the participants were ready for the interview, the researcher used audio - recorder to record the whole interview process. During the interview, the researcher asked questions specified in the interview protocol. However, follow-up questions were asked as part of the need for the participant to clarify or elaborate the responses. This study patterned guidelines of the National Ethical Standards for Health and Health Research of the Philippines 2017. Researcher' reflexivity were also taken into account.

Data Analysis. Analysis of data were done using Colaizzi's method (1978) of thematic analysis. This process of analysis involves sorting or coding the data into themes and categories by identifying and analysing repeating patterns that exist in the data. (1) Acquiring a Sense of Each Transcript. After conducting the interview personally and face-to-face to the participants, the researcher listened the audio-taped responses for several times. All responses were recorded verbatim. (2) Extracting Significant Statements. The transcripts were read and reread to identify and highlight the participants' experiences. These statements were highlighted on each page of every transcript using a luminous pen. It was then cut from the appropriate transcript and pasted on a separate sheet retaining the transcript, page and line number. (3) Formulation of Meanings. The researcher in this step attempts to formulate more general statements distilled from each text. (4) Organizing formulated meanings into clusters of themes. After formulating meanings from the significant statements extracted, the researcher arranged it to form clusters of themes. (5) Exhaustively describing the investigated phenomenon. In this stage of analysis, the researcher will integrate all the resulting ideas into an exhaustive description of the phenomenon. (6) Describing the fundamental structure of the phenomenon. Through the rigorous analysis, the researcher identified the fundamental structure or the essence of the experiential phenomenon as revealed through explication. (7) Returning to the Participants. Lastly, the researcher returned to the participants for validating the essence of the phenomenon. Trustworthiness of the study were ensured through credibility, transferability, dependability and confirmability (Lincoln \& Guba, 1985).

\section{RESULTS AND DISCUSSIONS}

\section{Profile of the Participants}

In this section, the summary of the participants' profile are presented in the light of providing their background in terms of sex, age, school assignment, date of first regular appointment. The school, however, were kept confidential as requested by the participants during the validation of results process. Even if it was reflected in the interview guide, the researcher decided to use pseudonyms in the discussion. The gathering of data on the survey of potential participants was conducted last June to July 2019. The in-depth interview of participants was conducted from August 2019 to January 2020. There were eight participants involved in this study. Each of these participants have different background profiles which is discussed below 
using their pseudonyms as well. In general, among the eight participants, the highest number of years as Teacher I was 30 years while the lowest is 10 years. Two participants fall on the youngest age at 33 while the oldest is 58. Six of eight participants had been transferred from one school to another while two were stationary. All of them are married but only one has no child yet.

\section{Themes on the Lived Experiences of Public School Teachers on Career Advancement Stagnation}

\section{Theme 1. Professional Learning and Development}

Common among the experiences of the participants is on how professional learning and development drives them to the phenomenon. The essence of this theme relates to their experiences as they attempt to advance their career while interacting with the administrators and human resource managers and staff. Educational qualifications and Trainings emerged as the subthemes.

Subtheme 1 Educational Qualifications. Seven of the eight participants highlighted the importance of educational qualifications in the teaching career as a product of professional development sessions in universities and colleges such as obtaining masteral units, masteral degree, among others. The participants also had tried applying for promotion. However, during the screening process, they were required to gain masteral units as part of their educational qualifications. Thus, when the participants attain less number of units than what is required or have not attended post-graduate studies, they were denied to undergo the screening process. These guidelines adhere to the Position Classification and Compensation Scheme for Teaching Positions in Elementary and Secondary Schools by the Department of Budget and Management (DBM) through ERF. But, it is just one of the options of the public school teachers on their career progression as reflected on the DBM Manual. Teachers can still undergo the process of evaluation and screening based on the latest Division Memorandum Number 707, series 209 dated November 13, 2019. It indicates that educational qualifications include Bachelor's Degree in Elementary or Bachelor's Degree with 18 Professional Units in Education if the applicant is a non-education graduate.

Subtheme 2: Trainings. Matthews et.al. (2004) defined learning as the intended outcome of training. Majority of the participants lack trainings to equip themselves with the advent of the $21^{\text {st }}$ century teaching-learning and the inevitable changes of the demands of the curriculum. Participants cited Information, Communication and Technology (ICT) Skills, Classroom Discipline and Management, Innovations and Strategies and Pupils' Behavior as their primary challenges in their day-to-day teaching. "Diri pareho han una, yana an IPCRF sugad hiton kinukurian ako kay diri man ako maaram mag computer, computer illiterate man ako." [Unlike before, IPCRF now is difficult for me because I do not know about computer, I am computer illiterate] [p.2, L.16], one participant exclaimed on the need to be provided with the $21^{\text {st }}$ century skills. Some participants resort to hiring other skilled individuals causing costly preparations in teaching thus leading to another financial expenses. There are trainings available and have been attended by some participants, however, it did not address the needs of the teachers.

Theme 2: Organizational Support. Majority of the participants mentioned the essence of support in the organization from school administrators and colleagues. The support system matters as the participants journey themselves in their career development. "Hira nala it nasiring 
na kinahanglan mo na ma promote kay 20 years $k a n a$ " [They are telling me that I need to be promoted because I am already 20 years (in service)] [p.5, L3], asserted by one of the participants on how administrators encouraged him to apply for promotion. Most of the participants claim that school heads usually encouraged teachers for promotion if you have served a significant number of teaching experience in the department. Participants are also asking advice from colleagues on how they underwent the process of promotion. On the other hand, some participants pointed out their experiences in the past stating, "Kun mayda hiton sugad hadto ba na panahon, siguro diri pa naabot hin mga 10 or 8 siguro nagpa rank na ak sabay pat aadi na mga kausa na nag eencourage na dudrugan kita para waray kulba" [If there is something like that before, maybe it will not reach 10 or 8 , perhaps, I was able to join my colleagues who are encouraging me to process the ranking so that we will not feel nervous] [p.4,L.19]. Hence, organizational support affects the career development of an individual.

Theme 3. Organizational Communication. Organizational communications had been one of the pressing concerns among the participants in terms of career advancement. One participant exclaimed, "Diri parehos yana na bisan kuan magagamit ngean kay kun aware la ak hadto bangin waray ak hadto kaiha" [Unlike now that even something can be used, if only I was aware of it, my promotion may not took so long][p.5, L.30]. "So you have to have units para maka apply ka ERF so may time din we pass some of the requirements pero it was too late kasi hindi kami ni sabihan ng early ng school head so parang ganun" [So you have to have units so you can apply $\mathrm{ERF}$, then there are times that we have to pass some of the requirements but it was too late because we were not told earlier by the school head] [p. 3, L.25]. Hence, the communication regarding career advancement should be clarified among the public school teachers. "Diri man ak maaram han process hadto na panahon" [I do not know the process that time] [p. 3, L.9], one participant emphasized on his experience on career advancement stagnation. Orientation was also done but with vagueness, lack of information on the documents to be submitted for promotion and what accomplishments will be submitted were also taken into account by the participants.

Theme 4. Work Environment. Majority of the participants shared about their experiences on their working environment. These includes workloads, work pressures, diversity of learners, and working beyond office hours. "Yana makuri ko it K to 12 kay more on paper works less na lugod iton actual teaching na samantala hadto less paper works yana more on paper works na" [Now it is difficult with the $\mathrm{K}$ to 12 because it is more on paper works, less actual teaching. Unlike before less paper works, now it is more on paper works] [p.3, L.8]

\section{Themes on the Reasons of Public School Teachers on Career Advancement Stagnation}

Theme 1. Financial Problem. Six of the eight participants experienced scarcity of financial resources. These results to unprocessed promotion documents, unending debts, unfinished postgraduate studies and family obligations. "Siyempre kulang man ako hin kwarta, tak asawa waray man trabaho so ako man tanan it financer ako it breadwinner kun baga" [I lack money, my husband has no job] [p. 5,L.33], as one participant exclaimed. Financial resources become one of the root causes among other challenges of the participants. "Dapat mayda ka mga trainings or continue an schooling. Mag aano man ako kay waray ako budget pag schooling” [You should have trainings and continue schooling. What will I do, I have no budget for schooling.] [p.4, L.32], added by one of the participants. 
Theme 2. Low Educational Qualifications. Most of the participants considered their educational qualifications as one of the main reason why they are experiencing career advancement stagnation. Participants are applying for promotion but were denied due to lack of masteral units. "Diri la ako hadto naka usa pagpasa. Han mayda na liwat ano nasiring na hoy pasa para T2 kadto na liwat ako pero diri na liwat qualified kay kinahanglan 32 units" [It was not just once tha I submitted. When there was a chance, I was told to submit for T2, I went there and I was not qualified again because it needs 32 units] [p. 4, L.32], one participant explained. Another participant added that "Nag apply ngani ako hadto ha division tapos waray ka approve kay an akon units na frozen na adto, waray na gamit tapos kailangan man talaga may may degree ka, masteral degree ba" [I applied in our division then it was not approve since my units were frozen. It has no credit and there is a need to really have the degree] [p.2, L. 26].

Theme 3. Promotion Anxiety. Half of the participants have low self- efficacy since they are not confident that they deserve the promotion and advancement. They believe that when you achieve advancement, promotion means bigger responsibilities and expectations. They go away with work pressure. Some teachers do not expect promotion because of less job roles. "Nadiri kasi ako sir hin pressure, gusto ko kasi la talaga hiya iton baga masayunay la ba" [I do not want pressure, I want easy tasks] [p.2, L.24], one participant shared.

Theme 4. Lack of Support. While career development is part of the human resource managers' tasks, the school managers and administrators are considered to be the front liners in planning the career of public school teachers. Most of the participants believed that the support of the administrators matter a lot. "Depende la liwat ha principal kun na care hit mga teachers danay waray gihap" [It depends on the principal if he cares the teachers, sometimes they do not.] [p. 5, L.21], the participant discussed. Another participant added that "Somewhere in school din kasi wala naming nagpupush sa akin na you have to walang nag eencourage sa akin so parang wala lang" [Because somewhere in school, no one is pushing me, no one encourages so it is nothing] [p. 3, L.13]

Theme 5. Career Decisions. Most of the participants do not prioritize career advancement and considered it as their career choice. Promotion becomes less priority due to family responsibilities, another career goal, and vocation. "Naka asawa man ako bagan nawarayan na ako interes kay siyempre iba naman an akon priority baga amo adto nawarayan na ako gana" [I get married then so I lost my interest because I changed my priority, thus I lost motivation] [p.3, L.26]. On the other hand, one participant considered teaching as a vocation as he said "Hindi ako nag aaspire na maging ano maging leader because I am enjoying my work. Gusto ko lang talaga na mag teach sa mga bata. "' I do not aspire to be a leader because I am enjoying my work. I really want to teach children] [p.1, 1.35].

\section{Themes on the Coping Mechanisms of Public School Teachers on Career Advancement Stagnation}

Theme 1. Positive Coping Mechanisms. All the participants shared positive coping mechanisms on the different challenges they have experienced on career advancement stagnation. They all agreed that acceptance and making resolutions can best display their attitude towards the experiences. "Waray man ok manla waray ak mahihimo kaya mot ira kuan patakaran, waray na ako hito magpirit, maeskwela nala ako masteral" [I can do nothing with that because that is their rule, I did not forced it, I will just pursuit masteral] [p. 3, L.10], as the 
participant shared. Participants also do their best everyday so that the administrators will let them undergo the process for career advancement.

Theme 2.Negative Coping Mechanisms. Even if all the participants discussed their positive coping mechanisms, five participants expressed their negative coping mechanisms as their way of facing the challenges of career advancement stagnation. These include feeling of inferiority, resorting to early retirement and resignation, feeling of disappointments and regrets. "Amo lagi iton naawa ako hit iba adto na hira naunahan na ak nira imbes ka level ko la it hira" [I feel envious with others that they levelled up over me even if we have the same level before] [p. 7. L.13]. The participants are also regretful with the situation and wishes to retire or resign soon, "Kun pwede ngani ako mag retire yana maretire ako kay makapoy na it Sistema hit DepEd bagat nadidis appoint ako" [If I can only retire now, I will retire because I am tired with the system of DepEd, I am dis appointed.] [p. 7, L.32]

\section{CONCLUSIONS}

Among the varied responses of the participants on the in-depth interview on the lived experiences, reasons and coping mechanisms of the challenges, the following conclusions are revealed:

1. Career advancement stagnation is a phenomenon experienced by public school teachers that involves two dimensions - individual and organizational dimensions.

2. The interaction between the two dimensions are overlapping that career development can be considered as a two - way process.

3. On lived experiences of public school teachers, professional learning and development, organizational support, organizational communication and work environment emerged as themes on the said phenomenon.

4. Lack of Financial Resources, low educational qualifications, promotion anxiety, lack of support and career decisions were the emerging themes on the reasons why the participants are experiencing career advancement stagnation.

5. Coping mechanisms employed by the participants involved positive coping mechanisms such as acceptance and making resolutions to handle the situation. However, there were noted negative coping mechanism considered such as the feeling of inferiority, resorting to early retirement and resignation, feeling of disappointments and regrets.

It is then necessary that intervention and enhancement programs be recommended to minimize the foregoing effects of career advancement stagnation. Intervention programs include, but not limited to, career guidance sessions, career orientation programs and career consultation programs. Enhancement programs will involve creating a clear guidelines and processes, policy formulation and revisiting the promotion and merit policies.

\section{REFERENCES}

Abele, A. E., Volmer, J., \& Spurk, D. (2012). Career stagnation: Underlying dilemmas and solutions in contemporary work environments. In Work and quality of life(pp. 107132). Springer, Dordrecht 
Cohen, L., Manion, L. and Morrison, K. (2011) Research Methods in education. $7^{\text {th }}$ edition, London : Routledge

Collaize, P.R. (1978). Reflection and Research in Psychology. Dubuque, IA. Kindall/Hunt.

Cruz, M. (2018). House to probe DepEd on promotion of teachers. Manila Standards Today. Retrieved from http://manilastandard.net

Demel, Barbara \& Shen, Yan \& Las Heras, Mireia \& Hall, Douglas \& Unite, J. (2014). Career success around the world: Its meaning and perceived influences in 11 countries. The International Journal of Human Resource Management. 1. 59-87

Farrell, T. S. (2014). 'I feel like I've plateaued professionally... gone a little stale': midcareer reflections in a teacher discussion group. Reflective practice, 15(4), 504517.

Glossary of Educational Reforms. (2013, August 28). Professional Development Retrieved June 11, 2019 from https://www.edglossary.org/professionaldevelopment

Kloosterman, V. (2018, August 31). The importance of continuing professional Development. Retrieved June 11, 2019 from http://www.continuingprofessionaldevelopment.com

Laverty, S. (2003). Hermenutic Phenomenology and phenomenology

Mayhew R. 2019. Advancement Vs. Promotion. Onlinesmallbusiness.com

Moustakas, C. (1994). Phenomenological research methods. Thousand Oaks, CA: Sage

Nachbagauer, A.G., \& Riedl, G. (2002). Effects of concepts of career plateaus on performance, work satisfaction and commitment. International journal of manpower, 23(8), 716-733.

Phifer, P. (2003) College Majors and Careers, Fifth Edition. New York, NY: Ferguson Publication.

Wirtanen, M. 2018. Career Advancement: What it is and how to achieve it. Onlinedegrees.com

Zamir, S.(2018). A Teaching Career: Mobility and Stagation. Athens Journal of Education. 5. 145-160. 39587/aje/ 
